\title{
TIME OF TRAVEL AND DISPERSION IN A SELECTED REACH OF ROBERTS CREEK, CLAYTON COUNTY, IOWA
}

By D.W. Kolpin and S.J. Kalkhoff

\section{U.S. GEOLOGICAL SURVEY}

Water-Resources Investigations Report 91-4145

Prepared in cooperation with the IOWA DEPARTMENT OF NATURAL RESOURCES, GEOLOGICAL SURVEY BUREAU

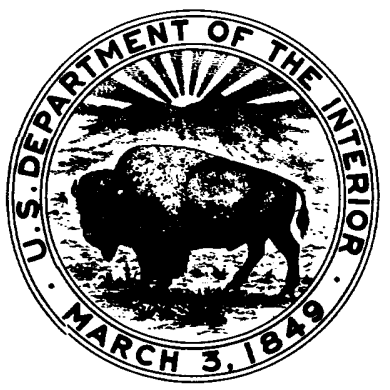

Iowa City, Iowa 1992 


\section{U.S. DEPARTMENT OF THE INTERIOR}

MANUEL LUJAN, JR., Secretary

\section{U.S. GEOLOGICAL SURVEY}

Dallas L. Peck, Director

District Chief

U.S. Geological Survey

Rm. 269, Federal Building

400 South Clinton Street

Iowa City, Iowa 52244
U.S. Geological Survey

Books and Open-File Reports

Denver Federal Center

Box 25425

Denver, Colorado 80225 


\section{CONTENTS}

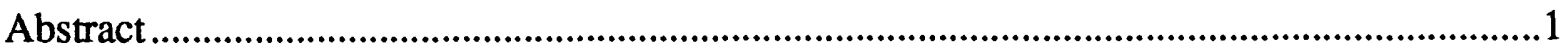

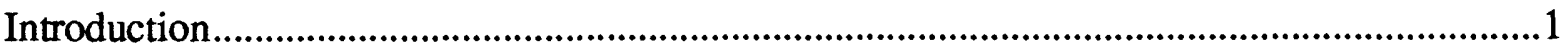

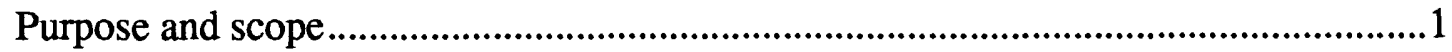

Description of the study area .......................................................................................2

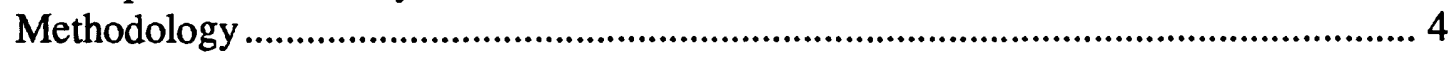

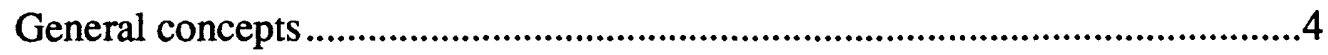

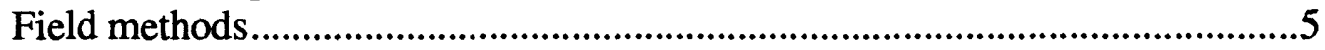

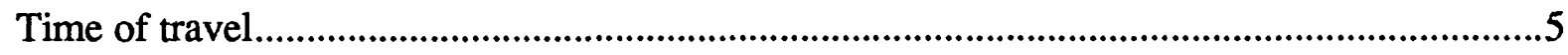

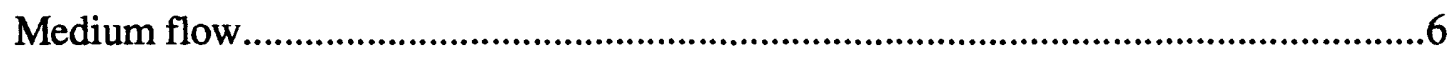

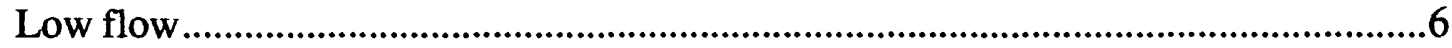

Interpolation of flow ...................................................................................................8

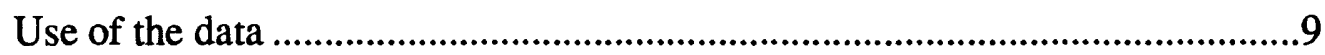

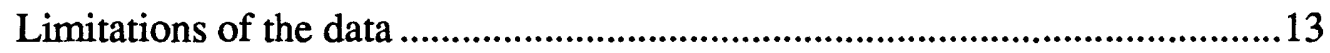

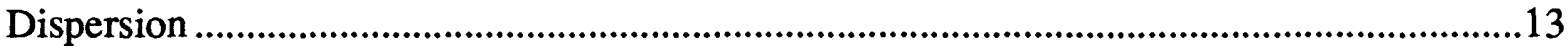

Summary

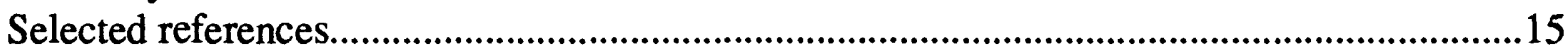

\section{ILLUSTRATIONS}

Figure 1. Map showing location of the study area, injection site, and sampling sites .2

Figures 2-8. Graphs showing:

2. Flow duration at Roberts Creek above Saint Olaf (site RC2) for period of record, March 1986 through September 1990, and for the two dyetracing tests

3. Typical response curve at a site downstream from an instantaneous-dyeinjection site

4. Dye concentrations at the sampling sites during medium flow (March 20-22, 1990) and low flow (April 30-May 12, 1990) 7 


\section{ILLUSTRATIONS--Continued}

Page

Figure 5. Velocity of the leading edge of the dye plume .................................................10

6. Velocity of the peak concentration of the dye plume ..........................................11

7. Velocity of the trailing edge of the dye plume ................................................12

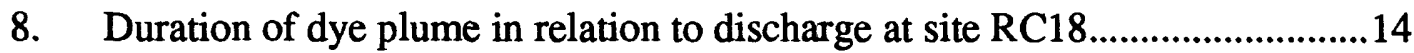

\section{TABLES}

Page

1. Traveltime for the dye plume during medium-flow conditions, March 20-22, 1990 8

2. Traveltime for the dye plume during low-flow conditions, April 30 to May 12, 1990

\section{CONVERSION FACTORS AND ABBREVIATIONS}

\section{Multiply}

foot $(\mathrm{ft})$

foot per second (ft/s)

cubic foot per second $\left(\mathrm{ft}^{3} / \mathrm{s}\right)$

inch (in.)

mile (mi)

mile per hour $(\mathrm{mi} / \mathrm{h})$

foot per mile $(\mathrm{ft} / \mathrm{mi})$
By

0.3048

0.3048

0.02832

25.40

1.609

1.609

0.1894
To obtain

meter

meter per second

cubic meter per second

millimeter

kilometer

kilometer per hour

meter kilometer 


\title{
TIME OF TRAVEL AND DISPERSION IN A SELECTED REACH OF ROBERTS CREEK, CLAYTON COUNTY, IOWA
}

\author{
By D.W. Kolpin and S.J. Kalkhoff
}

\section{ABSTRACT}

Time of travel and dispersion were determined in a 9.4-river-mile reach of Roberts Creek in northwestern Clayton County, lowa, in the spring of 1990. Time of travel was determined so that a discrete parcel of water could be sampled through the study area during medium to low streamflow conditions. Dispersion characteristics were determined to identify solute-transport differences under two streamflow conditions.

Time of travel was determined by dye tracing, using rhodamine WT as the tracer. One dyeinjection site and three sampling sites were used to measure time of travel. Two dye-tracing tests were conducted at discharges having flow-duration values of 48 and 80 percent. The discharges at the time of the two dye-tracing tests approximated medium- and low-flow conditions. The average stream velocity in the study area was 0.23 foot per second during medium-flow conditions, March 20 to 22,1990 , and 0.07 foot per second during low-flow conditions, April 30 to May 12, 1990. The injected dye dispersed in a plume that lasted about 18 hours during medium flow and about 64 hours during low flow at the downstream site.

\section{INTRODUCTION}

The eventual fate of the agricultural use of nitrogen fertilizers and pesticides in the environment is unknown. Numerous studies have indicated that runoff from precipitation transports these chemicals into nearby streams and lakes (Schuman and others, 1973; University Hygienic Laboratory, 1977, 1979, 1983; Hallberg and others, 1983; Goolsby and others, 1989). Once in the stream, the nitrate and ammonia from fertilizers are readily available for biological processes. Less is known of the fate of the pesticides in streams.

Previous investigations (Kalkhoff, 1989; Kalkhoff and Kuzniar, 1990) have indicated a decrease in both the concentration and load of nitrate and atrazine (a triazine herbicide) downstream in Roberts Creek during low-flow conditions. Loss of flow from seepage can account, at least partially, for decreases in the chemical load, but has no effect on chemical concentration. Consequently, the change in concentration might be due to physical processes, chemical processes, or the sampling procedure. Because chemical inputs into surface water might vary with time, changes in concentrations measured downstream might be because the same discrete parcel of water was not sampled at each sampling site.

To minimize sampling strategy as a possible source of variation in the concentrations of soluble substances due to changing input concentrations, a discrete parcel of water needs to be sampled as it moves through a particular reach of a stream. To do this, the time of travel from point to point within the reach needs to be estimated to calculate the arrival of the discrete parcel of water at each sampling site. Information about solute dispersion can be used to study the physical, chemical, and biological processes altering the solute as it moves downstream.

This study was conducted in cooperation with the Iowa Department of Natural Resources, Geological Survey Bureau.

\section{Purpose and Scope}

This report presents the results of a study to estimate the time required for soluble substances to move through a selected reach of Roberts Creek. The study consisted of two dyetracing tests conducted during medium- and low-flow conditions in Roberts Creek. Time of travel was calculated by injecting a dye tracer at the upstream site and measuring the time 
required for the dye plume to reach downstream sites. With this information, the same discrete parcel of water then can be sampled at several locations in the stream, minimizing sampling strategy as a possible source of variation in the concentrations of soluble substances. This time-of-travel information was used to conduct water-quality investigations in Roberts Creek during the same growing season.

\section{Description of the Study Area}

The study area is a 9.4-river-mi reach of
Roberts Creek located north of Saint Olaf in northwestern Clayton County, Iowa (fig. 1). The study area is in a region commonly called the Big Spring Basin, which is a ground-water basin mapped by Hallberg and others (1983) in an area of karst topography. In this area, carbonate rocks lie close to, or are exposed at, the land surface. Ridgetops are covered with as much as $20 \mathrm{ft}$ of windblown loess. The loess thickness decreases with distance from ridgetops, and in many places bedrock is exposed in the valleys and streambeds. The bedrock is composed of interbedded limestone and dolomite (Hallberg and others, 1983).

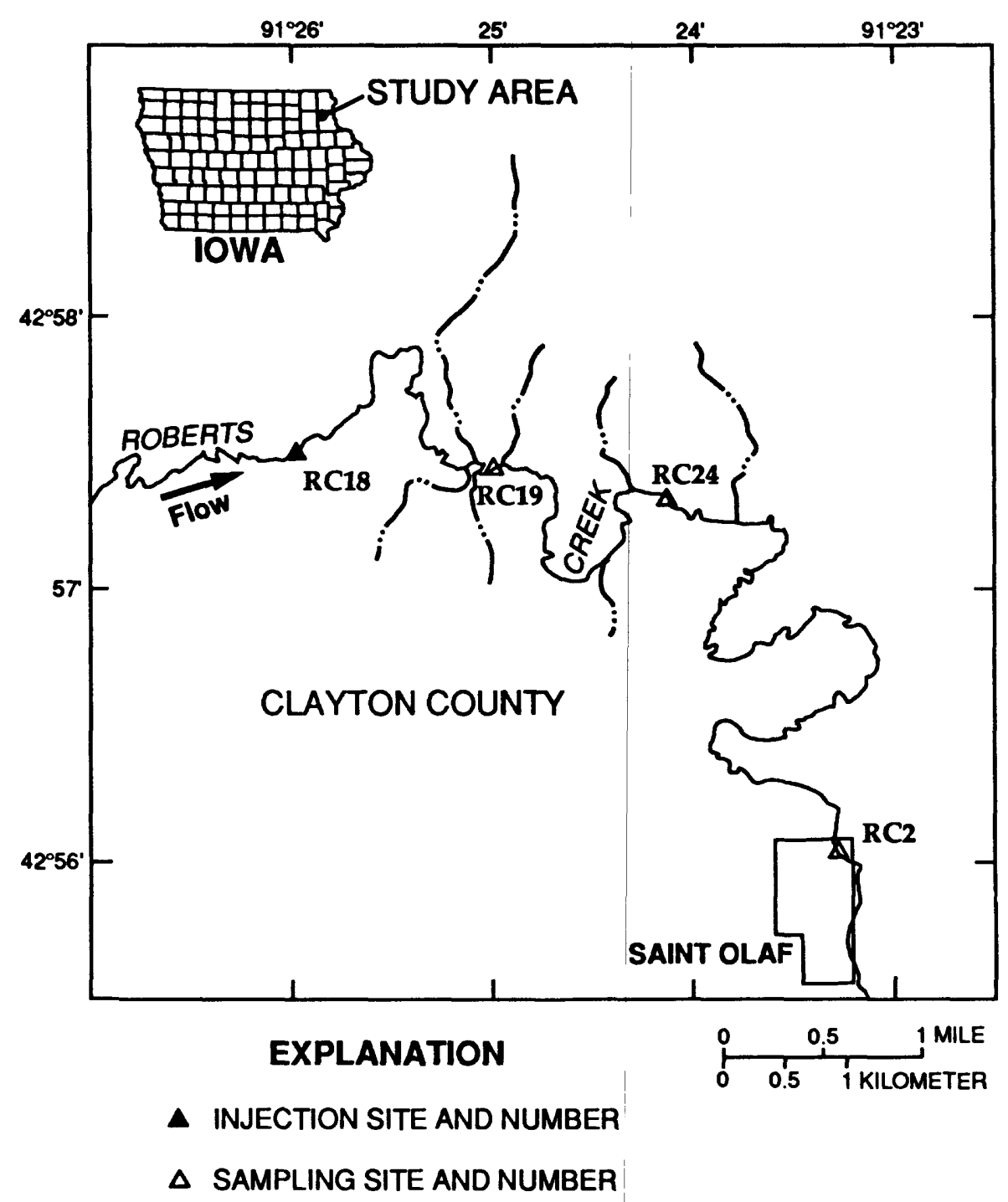

Figure 1. Location of the study area, injection site, and sampling sites. 
Bedrock in the study area is jointed and fractured, and solutional activity is evident. Water can readily seep from streams into the underlying bedrock through the joints fractures.

The study area extends from site $\mathrm{RC} 18$ downstream 9.4 river mi to site RC2 (fig. 1). Two additional sites were used to define the time of travel in the study area. Site RC19 is 2.1 river mi downstream from site $\mathrm{RC} 18$, and site $\mathrm{RC} 24$ is 3.95 river mi downstream from site RC18. The streambed slope is about $10 \mathrm{ft} / \mathrm{mi}$ through the study area, and the channel varies in width from about 5 to $30 \mathrm{ft}$. In ponded areas, the streambed consists of silt, but the stream also flows over large sections of exposed bedrock. Data from other studies (Hallberg and others, 1983; Kalkhoff, 1989) indicate that water is lost from the stream into underlying aquifers throughout this entire 9.4-river-mi reach. There are seven intermittent streams that drain into the study area. These intermittent streams only flow during periods of high runoff, which generally occur during snowmelt and after intense rainfall. No perennial streams discharge into the study area.

Vegetative cover of a $100-\mathrm{ft}$ wide riparian zone on either side of Roberts Creek, defined as the streambank in this report, is not uniform within the study area. About 80 percent of the 2.1 river mi of streambank between sites $\mathrm{RC} 18$, and RC19 (fig. 1) is wooded. During the time of this study, numerous fallen, dead trees were completely or partially across the channel within this subreach, and floating twigs and branches accumulated on the upstream side of these obstructions. A small beaver dam constructed of branches and corn stalks was about 0.75 river mi downstream from site RC18. A typical cross section in this subreach has dense timber on one side of the stream and a thin buffer of trees and then corn fields on the opposite side of the stream.

About 30 to 40 percent of the 1.85 river mi of streambank between sites RC19 and RC24 (fig. 1) is wooded. The majority of the remaining streambank in this subreach is planted in corn interspersed with some pasture. According to local residents, there is a sinkhole in the streambed about 1.1 river mi downstream from site RC19.

About 20 to 40 percent of the 5.45 river mi of streambank between sites RC24 and RC2 (fig. 1) is wooded. Substantial parts of the remaining streambank are planted in corn within this subreach. About 0.50 to $1.0 \mathrm{mi}$ of the center part of this subreach has a large, steep cutbank that is densely wooded. The streambank of the downstream 0.25 to 0.5 river $\mathrm{mi}$ of this subreach is in permanent pasture. Emergent vegetation in the stream channel increases with distance downstream in this subreach. According to local residents, there is a sinkhole in the streambed about 2 to 3 river mi downstream from site RC24.

Streamflow at the most downstream site, site RC2, has been recorded since March 1986. The flow-duration curve, which is a plot of discharge against the percentage of time that discharge is equaled or exceeded, for the period of record is shown in figure 2. During the period of record, flow equaled or exceeded 1 $\mathrm{ft}^{3} / \mathrm{s}$ about 74 percent of the time, equaled or exceeded $10 \mathrm{ft}^{3} / \mathrm{s} 33$ percent of the time, and equaled or exceeded $20 \mathrm{ft}^{3} / \mathrm{s}$ about 17 percent of the time. Median flow was $5.6 \mathrm{ft}^{3} / \mathrm{s}$. The corresponding flow durations for the dyetracing tests also are shown in figure 2 . The streamflow at site $\mathrm{RC} 2$ was about $6.1 \mathrm{ft}^{3} / \mathrm{s}$ when the peak dye concentration was measured March 22 during the first dye-tracing test. This discharge, which is equaled or exceeded about 48 percent of the time, generally represents a medium-flow condition. The streamflow was about $0.7 \mathrm{ft}^{3} / \mathrm{s}$ when the peak dye concentration was measured May 8 during the second dyetracing test. This discharge, which is equaled or exceeded about 80 percent of the time, represents a low-flow condition. 


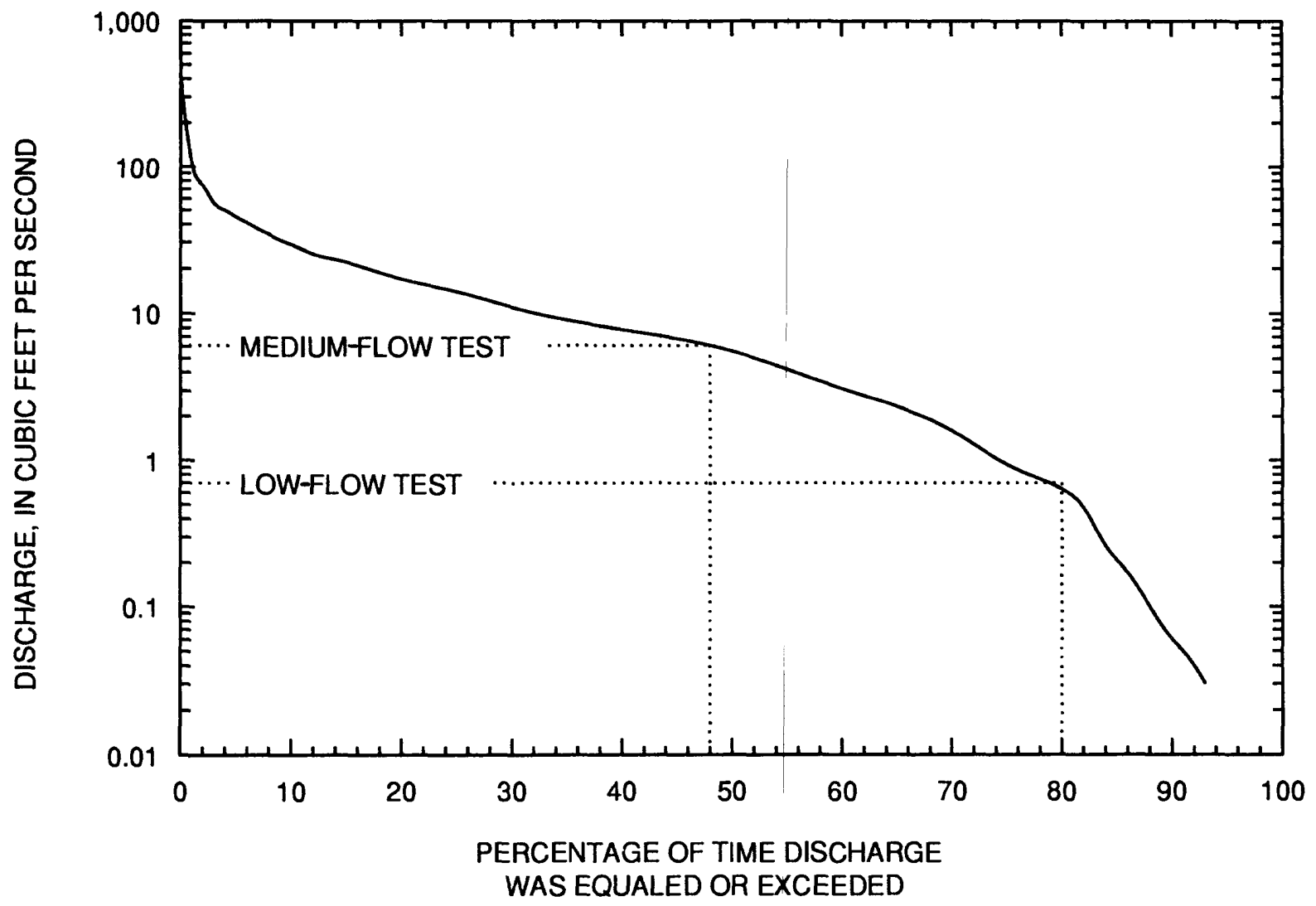

Figure 2. Flow duration at Roberts Creek above Saint Olaf (site RC2) for period of record, March 1986 through September 1990, and for the two dye-tracing tests.

\section{Methodology}

\section{General Concepts}

Time of travel refers to the movement of water or waterborne solutes from point to point in a stream during steady or gradually varied streamflow conditions (Kilpatrick and Wilson, 1989, p. 1). To measure the time of travel between selected sites, a tracer is injected at an upstream site, and concentrations are measured at downstream sites as a function of time. The tracer used in this study was rhodamine WT dye. This dye was selected because it is soluble in water, generally is easy to detect, has a fluorescence in a part of the spectrum not common to materials generally detected in water, is harmless in small concentrations (Steinheimer and Johnson, 1986, p. 48), and is reasonably stable in normal water environments (Wilson and others, 1986, p. 3).

Concentrations of the dye in samples from a downstream site are plotted against the elapsed time since injection to obtain the response curve (fig. 3 ). The leading edge of the dye plume is the first detection of a dye concentration greater than background fluorescence, the peak is the time when the dye concentration is the greatest, and the trailing edge is the time when the dye concentration decreases to 10 percent of the peak concentration. The response curve then is used to determine time of travel and dispersion characteristics of the stream. Mean time of travel for flow to a sampling point is the elapsed time from dye injection to the peak of the response curve. 


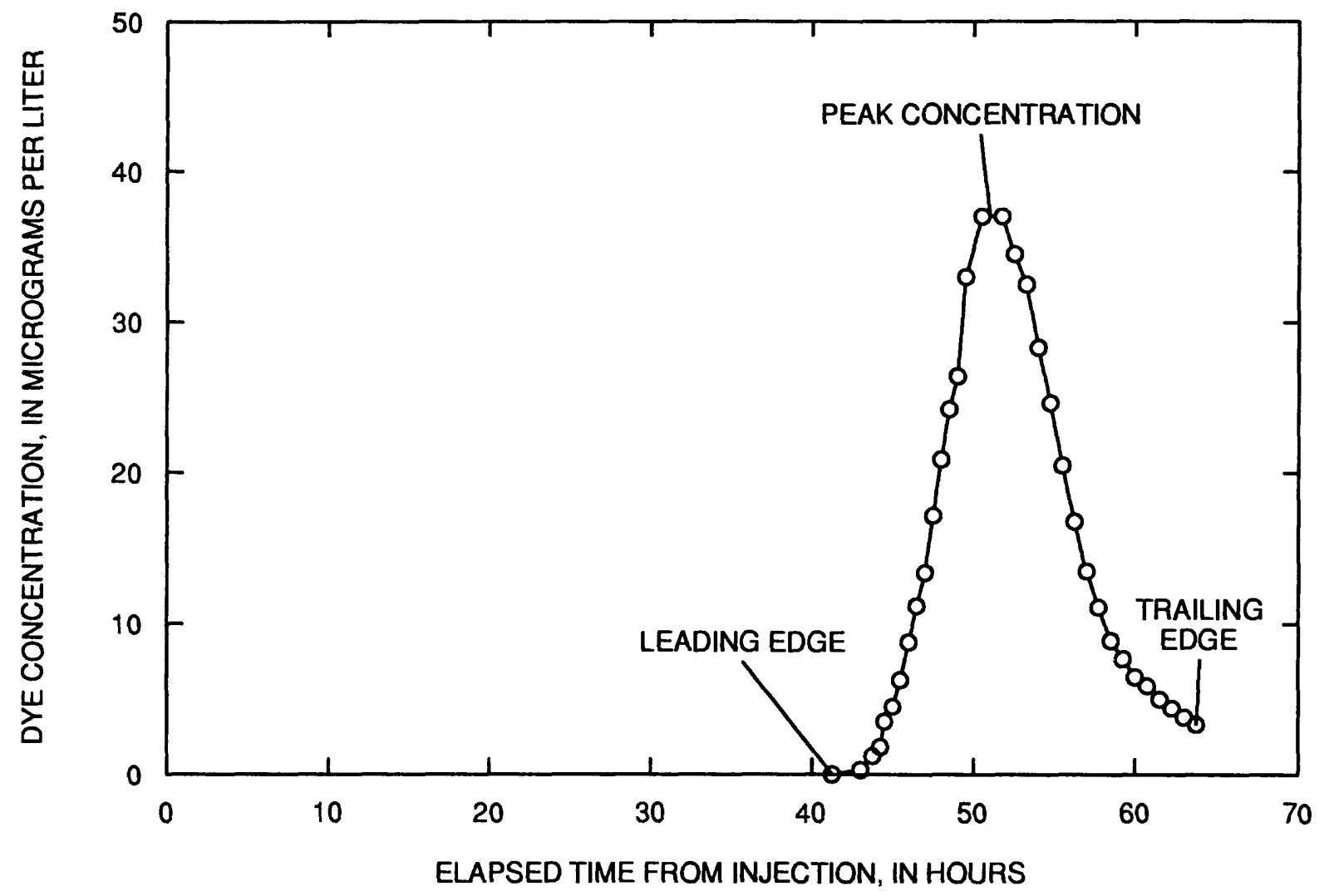

Figure 3. Typical response curve at a site downstream from an instantaneous-dye-injection site. Data shown are dye concentrations at site RC24 after dye injection at site RC18 on April 30, 1990.

\section{Field Methods}

One dye-injection site and three sampling sites were used to measure time of travel and dispersion in the study area (fig. 1). The farthest downstream sampling site, site RC2, was at a continuous-record gaging station. A time-of-travel test commenced with the slug injection of rhodamine WT dye in the center of flow at site RC18. The time of injection was recorded. Water samples were collected at the downstream sites using a combination of manual grab samples and an automatic sampler. The use of an automatic sampler was effective and greatly decreased personnel needs. Sampling frequency ranged from 15 minutes to 3 hours. The dye concentrations in the samples were measured using a fluorometer (Wilson and others, 1986). The sampling time and dye concentration were recorded for later analyses. Water samples were tested at each site until the dye concentration decreased to 10 percent of the peak concentration. One discharge measurement was made at the injection site and each of the sampling sites at the time the dye was present.

\section{TIME OF TRAVEL}

Time of travel in the study area was determined for a medium-flow condition (March 20 to 22, 1990) and a low-flow condition (April 30 to May 12, 1990). Because of the short mixing length for this size of stream compared to the length of the first subreach (2.1 mi), it was felt that a slug injection of dye at site $\mathrm{RC} 18$, instead of the dye being completely mixed before reaching site RC18, would have minimal effect on measured velocities. The 
results of this study reflect conditions that existed at the time of the dye-tracing tests.

\section{Medium Flow}

A dye-tracing test was conducted during March 20-22, 1990, during a medium-flow condition for Roberts Creek. The ice cover broke up 11 days before the start of this test. The streamflow in the study area from the ice melt and two subsequent rainstorms was slowly decreasing and was $7.6 \mathrm{ft}^{3} / \mathrm{s}$ at the time of injection at site $\mathrm{RC} 18$. The last rainstorm occurred 5 days before the start of the dye test.

About $680 \mathrm{~mL}$ (milliliters) of rhodamine WT dye were injected at site RC18 on March 20,1990 , at 0710 hours. The peak concentration of the dye plume moved through the entire study area in about 59 hours, which is an average velocity of $0.23 \mathrm{ft} / \mathrm{s}$. The response curve is shown in figure 4 , and time of travel is summarized in table 1 for the dye plume during this medium-flow condition. The peak concentration of the dye plume had a velocity of $0.27 \mathrm{ft} / \mathrm{s}$ through the subreach between sites $\mathrm{RC} 18$ and $\mathrm{RC} 19,0.33 \mathrm{ft} / \mathrm{s}$ through the subreach between sites RC19 and RC24, and $0.20 \mathrm{ft} / \mathrm{s}$ through the subreach between sites RC24 and $\mathrm{RC} 2$. When the dye concentration peaked at sampling site RC2 on March 22, the flowduration value for the study area was 48 percent.

The dye plume moved more quickly through the second subreach (sites RC19RC24) than through the first subreach (sites $\mathrm{RC18}-\mathrm{RC} 19)$. This pattern in dye velocity can be explained by the ponding effect caused by the fallen trees and the beaver dam in the first subreach. The ponding effect in this subreach causes backwater that decreases velocity.

Several factors might have affected the time of travel of this medium-flow test. The cold nighttime temperatures on March 20 and 21 caused a thin layer of ice to form on parts of the stream. About $1 \mathrm{ft}$ of nearshore ice formed in the riffles, the pooled areas were about 60 percent ice covered, and ice formed around exposed rocks in the stream. This thin layer of ice persisted into part of the morning hours. The ice might have tended to decrease velocities near the water surface, attenuating the dye plume between sites RC18-RC19 and sites RC24-RC2.

About 0.2 in. of rain fell on the study area during a 24-hour period on March 21 and 22. The dye plume had already moved past the first two sampling sites; consequently, the rain might have affected the time of travel from site RC24 to site RC2. The gage height for the continuous-record gaging station at site $\mathrm{RC} 2$ did not increase substantially, however, indicating that the time of travel was not affected appreciably by this rain.

Discharge measurements indicated that the study area lost less flow than during previous measurements at similar stages. Two reasons might account for the difference. First, the streambed is a dynamic environment. Sediment is eroded and deposited according to the dynamics of the flow. Increased flow after snowmelt might have deposited sediment in exposed bedrock fractures and decreased the rate of seepage from the stream. Second, additional water resulting from snowmelt and rainfall might have been entering the study area in various subreaches. This additional water might have been derived from either a change in the ground-water flow system--higher local water table--or from surface-water inflow to the study area from the intermittent streams. Four of the seven intermittent streams, however, were observed to have no flow, and therefore, it is unlikely that much surface water was flowing into the study area during this dyetracing test.

\section{Low Flow}

A dye-tracing test was conducted during 


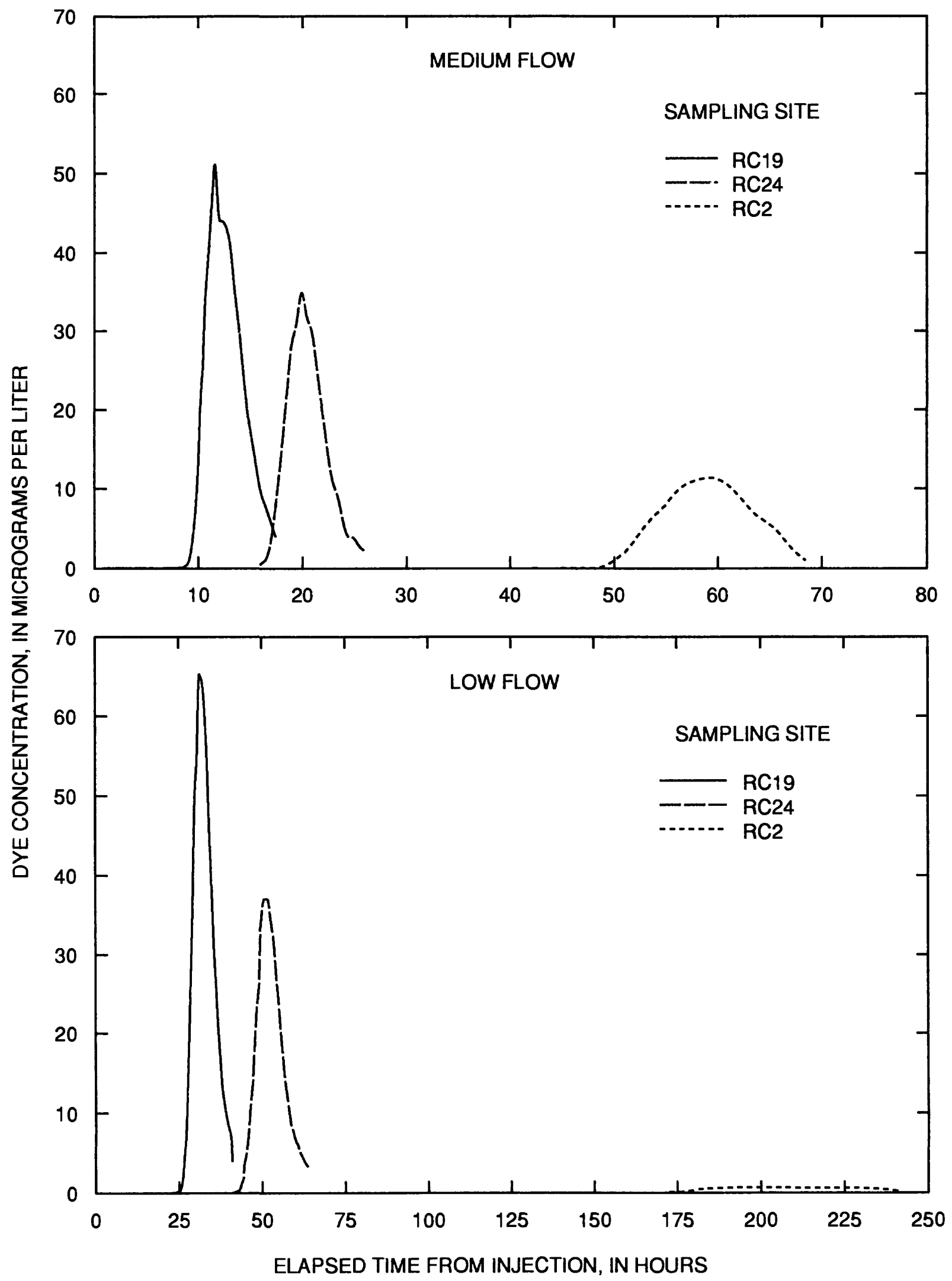

Figure 4. Dye concentrations at the sampling sites during medium flow (March 20-22, 1990) and low flow (April 30-May 12, 1990). 
Table 1. Traveltime for the dye plume during medium-flow conditions, March 20-22, 1990

[Cumulative traveltime values might not equal the exact sum of the individual traveltime values due to independent rounding. Units: mi, miles; $h$, hours]

\begin{tabular}{|c|c|c|c|c|c|c|c|c|}
\hline \multirow[b]{2}{*}{$\begin{array}{c}\text { Site } \\
\text { (fig. 1) }\end{array}$} & \multicolumn{2}{|c|}{ Distance (mi) } & \multicolumn{2}{|c|}{ Leading edge (h) } & \multicolumn{2}{|c|}{$\begin{array}{c}\text { Peak } \\
\text { concentration (h) }\end{array}$} & \multicolumn{2}{|c|}{ Trailing edge (h) } \\
\hline & $\begin{array}{c}\text { Between } \\
\text { adjacent } \\
\text { sites }\end{array}$ & $\begin{array}{c}\text { From } \\
\text { injection } \\
\text { point }\end{array}$ & $\begin{array}{l}\text { Travel- } \\
\text { time }\end{array}$ & $\begin{array}{c}\text { Cumu- } \\
\text { lative } \\
\text { travel- } \\
\text { time }\end{array}$ & $\begin{array}{l}\text { Travel- } \\
\text { time }\end{array}$ & $\begin{array}{c}\text { Cumu- } \\
\text { lative } \\
\text { travel- } \\
\text { time }\end{array}$ & $\begin{array}{l}\text { Travel- } \\
\text { time }\end{array}$ & $\begin{array}{c}\text { Cumu- } \\
\text { lative } \\
\text { travel- } \\
\text { time }\end{array}$ \\
\hline $\mathrm{RC} 18$ & 0 & 0 & 0 & 0 & 0 & 0 & 0 & 0 \\
\hline RC19 & 2.1 & 2.1 & 8.9 & 8.9 & 12 & 12 & 17 & 17 \\
\hline RC24 & 1.85 & 3.95 & 7.5 & 16 & 8 & 20 & 8 & 26 \\
\hline $\mathrm{RC} 2$ & 5.45 & 9.4 & 33 & 49 & 40 & 59 & 41 & 67 \\
\hline
\end{tabular}

April 30 to May 12, 1990, during a low-flow condition for Roberts Creek. At the start of this dye-tracing test, the flow of Roberts Creek in the study area was decreasing slowly and was $4.3 \mathrm{ft}^{3} / \mathrm{s}$ at the time of injection at site $\mathrm{RC} 18$. No precipitation had fallen for 2 days before the start of this test.

About $750 \mathrm{~mL}$ of rhodamine WT dye were injected at site $\mathrm{RC} 18$ on April 30 at 1330 hours. The peak concentration of the dye plume moved through the entire study area in about 200 hours, which is an average velocity of 0.07 $\mathrm{ft} / \mathrm{s}$. The response curve is shown in figure 4 and time of travel is summarized in table 2 for the dye plume during this low-flow condition. The peak concentration of the dye plume had a velocity of $0.10 \mathrm{ft} / \mathrm{s}$ through the subreach between sites RC18 and RC19, $0.14 \mathrm{ft} / \mathrm{s}$ through the subreach between sites RC19 and $\mathrm{RC} 24$, and $0.05 \mathrm{ft} / \mathrm{s}$ through the subreach between sites RC24 and RC2. When the dye concentration peaked at sampling site RC2 on May 8, the flow-duration value for the study area was 80 percent.

The second subreach again had a faster dye velocity than did the first subreach, as was the case for the dye-tracing test during mediumflow conditions. The fallen trees and beaver dam in the first subreach (sites RC18-RC19) again might have affected time of travel by decreasing dye velocity.

About 0.32 in. of rain fell during a 24-hour period on May 3 and 4. The dye plume had moved past the first two sampling sites so the precipitation did not affect time of travel from site $\mathrm{RC} 18$ to site RC24. The gage height increased only $0.03 \mathrm{ft}$ at site RC2, indicating that the rain only minimally affected the dye plume from site RC24 to site RC2.

About 1.35 in. of rain fell during a 10-hour period beginning at 0100 hours on May 9. The dye concentration had already peaked at site RC2; thus, this rain only affected the time of travel of the trailing edge of the dye plume. Equations in Kilpatrick and Wilson (1989) were used to reconstruct the time of travel of the trailing edge of the dye plume from site $\mathrm{RC} 24$ to site $\mathrm{RC} 2$.

\section{Interpolation of Flow}

Curves for predicting time of travel for a 
Table 2. Traveltime for the dye plume during low-flow conditions, April 30 to May 12, 1990

[Cumulative traveltime values might not equal the exact sum of the individual traveltime values due to independent rounding. Units: mi, miles; h, hours]

\begin{tabular}{|c|c|c|c|c|c|c|c|c|}
\hline \multirow[b]{2}{*}{$\begin{array}{c}\text { Site } \\
\text { (fig. 1) }\end{array}$} & \multicolumn{2}{|c|}{ Distance (mi) } & \multicolumn{2}{|c|}{ Leading edge (h) } & \multicolumn{2}{|c|}{$\begin{array}{c}\text { Peak } \\
\text { concentration (h) }\end{array}$} & \multicolumn{2}{|c|}{ Trailing edge (h) } \\
\hline & $\begin{array}{c}\text { Between } \\
\text { adjacent } \\
\text { sites }\end{array}$ & $\begin{array}{l}\text { From } \\
\text { injection } \\
\text { point }\end{array}$ & $\begin{array}{c}\text { Travel- } \\
\text { time }\end{array}$ & $\begin{array}{c}\text { Cumu- } \\
\text { lative } \\
\text { travel- } \\
\text { time }\end{array}$ & $\begin{array}{c}\text { Travel- } \\
\text { time }\end{array}$ & $\begin{array}{c}\text { Cumu- } \\
\text { lative } \\
\text { travel- } \\
\text { time }\end{array}$ & $\begin{array}{c}\text { Travel- } \\
\text { time }\end{array}$ & $\begin{array}{c}\text { Cumu- } \\
\text { lative } \\
\text { travel- } \\
\text { time }\end{array}$ \\
\hline RC18 & 0 & 0 & 0 & 0 & 0 & 0 & 0 & 0 \\
\hline RC19 & 2.1 & 2.1 & 25 & 25 & 32 & 32 & 41 & 44 \\
\hline $\mathrm{RC} 24$ & 1.85 & 3.95 & 18 & 43 & 19 & 50 & 23 & 64 \\
\hline $\mathrm{RC} 2$ & 5.45 & 9.4 & 136 & 178 & 149 & 200 & 178 & $* 242$ \\
\hline
\end{tabular}

*Estimated due to rainfall during dye test.

broad range of flows were constructed using the data obtained from the medium- and lowflow dye-tracing tests. A plot of dye velocity (stream-reach length divided by time of travel) as a function of discharge at injection site $\mathrm{RC} 18$ for the two dye-tracing tests is shown in figures 5 through 7 . Straight lines were drawn through the two points for each stream reach to obtain incremental dye velocities for the leading edge (fig. 5), peak concentration (fig. 6), and trailing edge (fig. 7). A linear interpolation (on a logarithmic scale) between the data for the two dye-tracing tests is the best model given the data available (Kilpatrick and Wilson, 1989).

\section{Use of the Data}

The objective of this study was to estimate the time required for soluble substances to move to any point downstream from injection site $\mathrm{RC} 18$ for a range of discharges at site RC18. Consequently, a discrete parcel of water can be followed through the study area. The only data needed to use figures 5 through 7 are stream distance from injection site RC18 to the sampling sites and the discharge at injection site $\mathrm{RC} 18$.

The following is an example of how the dye-velocity/discharge curves can be used: A particular investigation needs the time required for a solute to arrive at sampling sites located $2.1,3.95,6.95$, and 9.4 river mi downstream from site RCl8. A discharge of $5 \mathrm{ft}^{3} / \mathrm{s}$ was measured at RC18 at 1200 hours on June 15 .

o When will the peak solute concentration arrive at the sampling site 2.1 river mi downstream from site RC18?

Procedure: This sampling site (site RC19) is at the downstream end of the first subreach (fig. 1). With a discharge of $5 \mathrm{ft}^{3} / \mathrm{s}$ at site $\mathrm{RC} 18$, the velocity of water through the subreach $(0.088$ $\mathrm{mi} / \mathrm{h}$ ) is obtained from figure 6. Time of travel is calculated by dividing distance $(2.1 \mathrm{mi})$ by velocity 


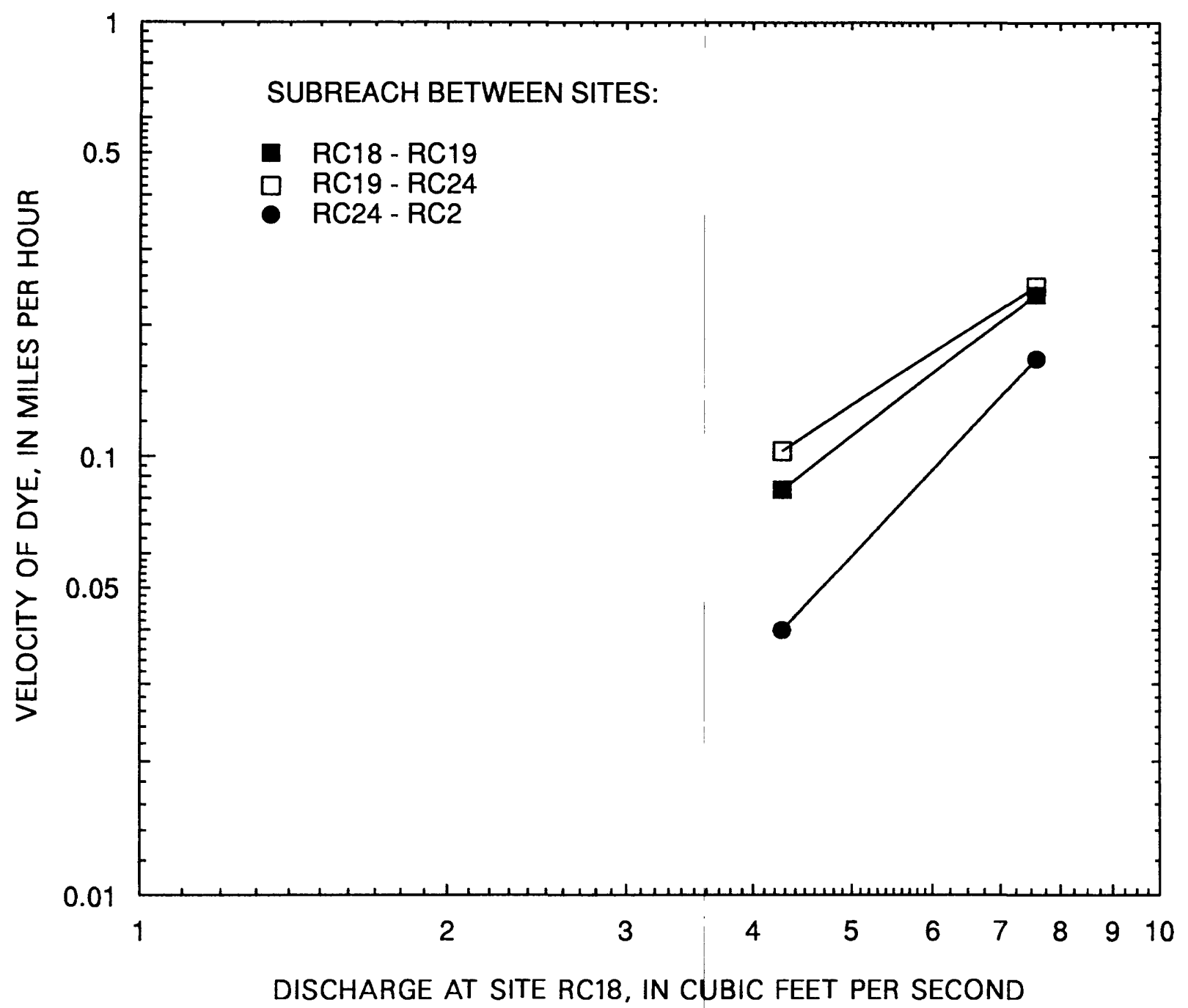

Figure 5. Velocity of the leading edge of the dye plume.

$(0.088 \mathrm{mi} / \mathrm{h})$. The result is 23.9 hours. Thus, the sample needs to be collected on June 16 at 1155 hours.

Because the velocity is not uniform through the entire study area, the time of travel needs to be calculated for each subreach and then added together to obtain the total time of travel. The following examples indicate how to calculate time of travel in several such situations.

o When will the peak solute concentration arrive at the sampling site 3.95 river mi downstream from site RC18?
Procedure: This sampling site (site RC24) is at the downstream end of the second subreach (fig. 1) and is 1.85 river mi downstream from site RC19. With a discharge of $5 \mathrm{ft}^{3} / \mathrm{s}$ at site $\mathrm{RC} 18$, the velocity of water through the second subreach $(0.12 \mathrm{mi} / \mathrm{h})$ is obtained from figure 6. Time of travel is calculated by dividing distance from the beginning of the subreach $(1.85 \mathrm{mi})$ by velocity $(0.12 \mathrm{mi} / \mathrm{h})$. The result is 15.4 hours. The 


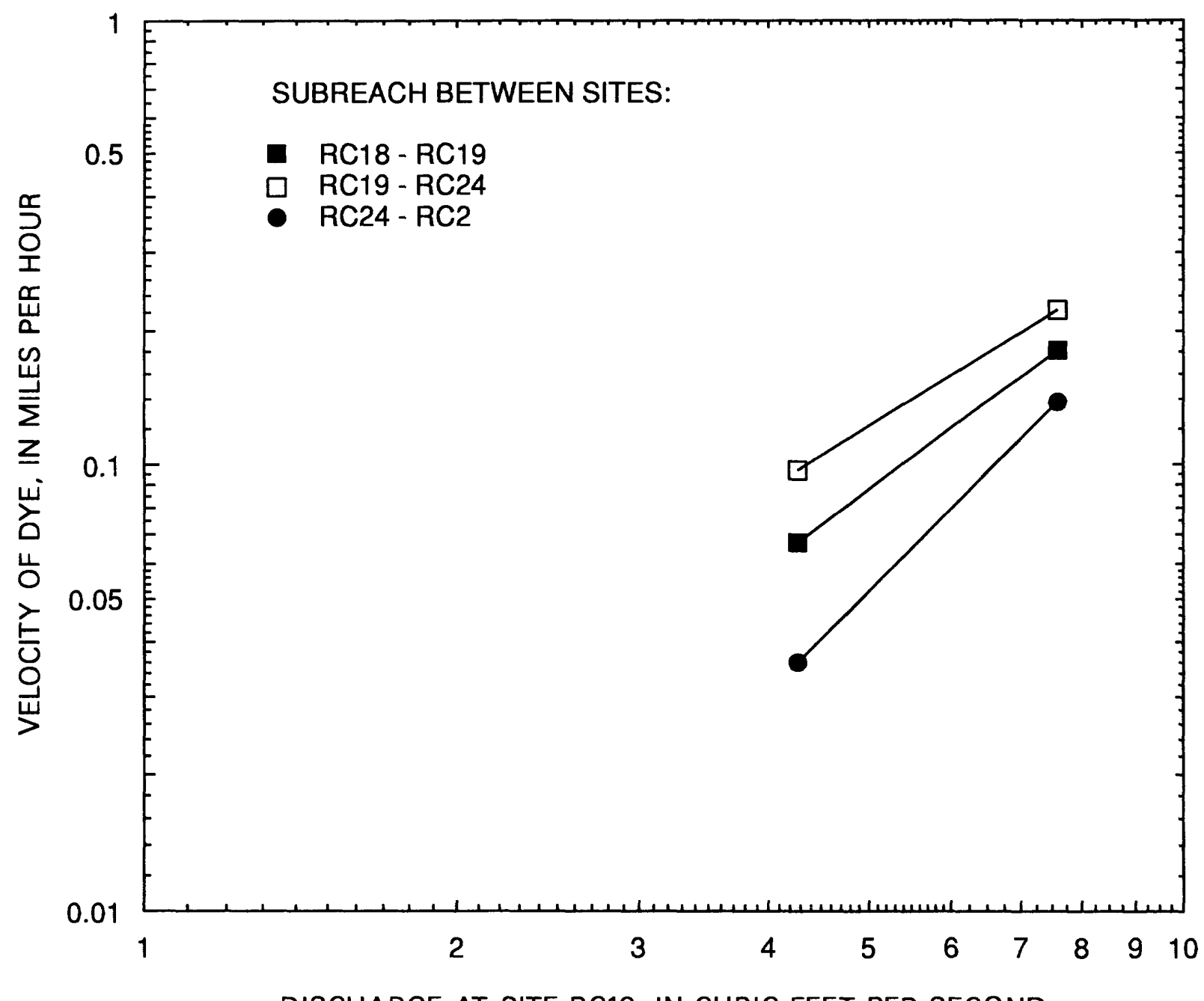

DISCHARGE AT SITE RC18, IN CUBIC FEET PER SECOND

Figure 6. Velocity of the peak concentration of the dye plume.

cumulative time of travel (time of travel in the first subreach, 23.9 hours; plus time of travel in the second subreach, 15.4 hours) from site $\mathrm{RC} 18$ is 39.3 hours. Thus, the sample needs to be collected on June 17 at 0320 hours.

o When will the peak solute concentration arrive at the sampling site 6.95 river mi downstream from site RC18?

Procedure: This sampling site is within the third stream subreach (fig. 1) and is 3.0 river mi downstream from site RC24. With a discharge of $5 \mathrm{ft}^{3} / \mathrm{s}$ at site $\mathrm{RC} 18$, the velocity of water through the third stream subreach $(0.052 \mathrm{mi} / \mathrm{h})$ is obtained from figure 6. Time of travel is calculated by dividing distance from the beginning of the subreach $(3.0 \mathrm{mi})$ by velocity $(0.052 \mathrm{mi} / \mathrm{h})$. The result is 57.7 hours. The cumulative time of travel from site RC18 (time of travel in the first subreach, 


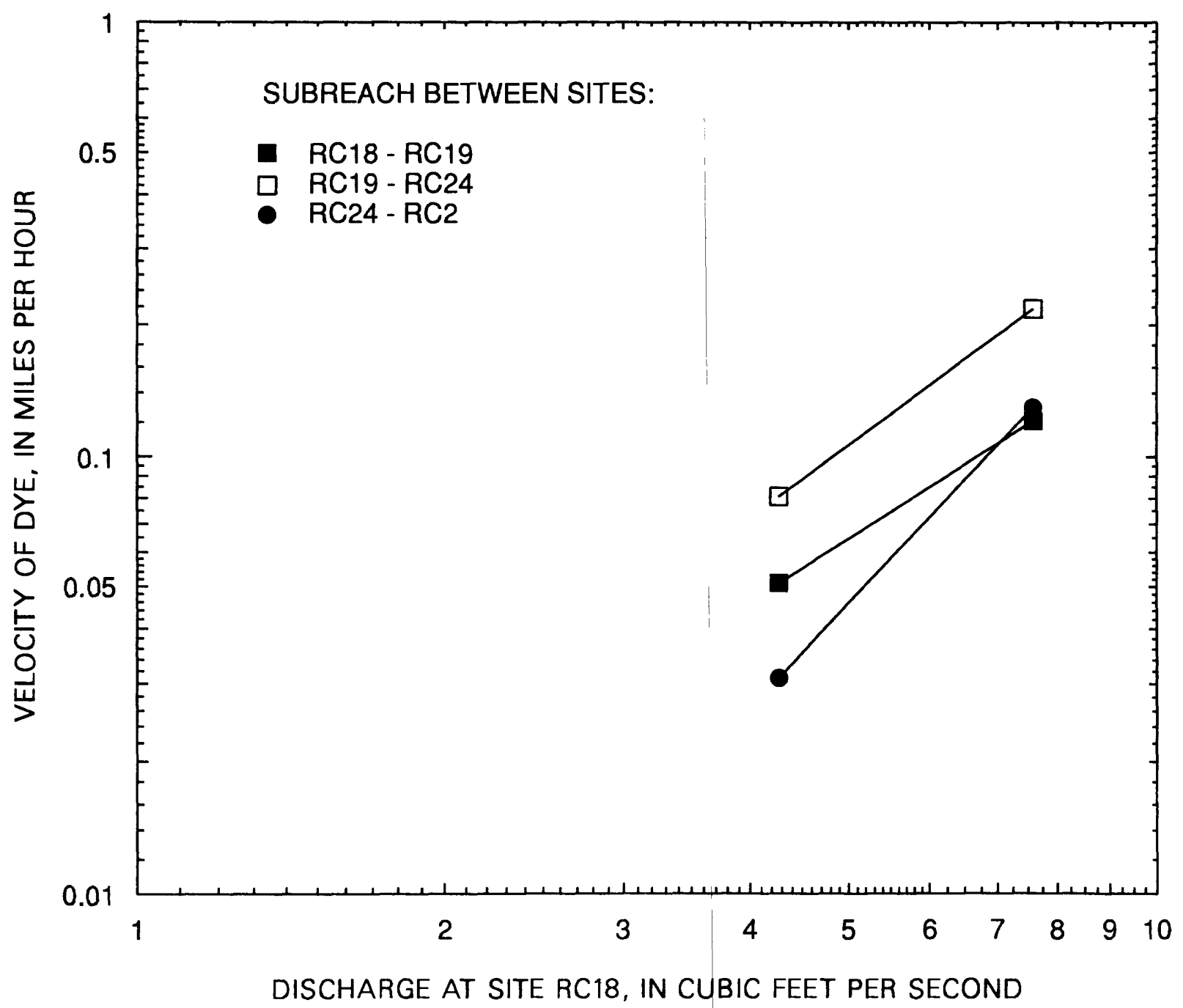

Figure 7. Velocity of the trailing edge of the dye plume.

23.9 hours; plus time of travel in the second subreach, 15.4 hours; plus time of travel in the first 3.0 $\mathrm{mi}$ of the third subreach, 57.7 hours) is 97.0 hours. Thus, the sample needs to be collected on June 19 at 1300 hours.

o When will the peak solute concentration arrive at the sampling site 9.4 river mi downstream from site RC18?

Procedure: This sampling site (site RC2) is at the downstream end of the third subreach (fig. 1) and is 5.45 river mi downstream from site RC24. With a discharge of $5 \mathrm{ft}^{3} / \mathrm{s}$ at site $\mathrm{RC} 18$, the velocity of water through the third stream subreach $(0.052 \mathrm{mi} / \mathrm{h})$ is obtained from figure 6. Time of travel is calculated by dividing distance from the beginning of the subreach $(5.45 \mathrm{mi})$ by velocity $(0.052 \mathrm{mi} / \mathrm{h})$. The result is 104.8 hours. The cumulative time of travel from site RC18 (time of 
travel in the first subreach, 23.9 hours; plus time of travel in the second subreach, 15.4 hours; plus time of travel in the third subreach, 104.8 hours) is 144.1 hours. Thus, the sample needs to be collected on June 21 at 1205 hours.

\section{Limitations of the Data}

Certain limitations apply to the use of the data to calculate time of travel:

1. The time-of-travel data for the study area of Roberts Creek are applicable during steady or gradually changing streamflow conditions. Large errors in the time of travel might occur if the results of this study are used during unsteady streamflow conditions, such as during storm runoff.

2. The time-of-travel data are most accurate during fair weather conditions. Substantial precipitation will cause changes in stream discharge, altering the time of travel. Precipitation also might change the concentrations of watersoluble constituents that might be under investigation.

3. The time-of-travel data are only valid for water or water-soluble constituents. The movement of substances that float on the surface (oil, for example) or that settle to the streambed (sediment) cannot be accurately estimated using these results.

4. The time-of-travel data are accurate only within the study area. Hydrologic and physical characteristics of Roberts Creek outside the study area were not studied.

5. Extrapolation of the time-of-travel data for discharges substantially less than or greater than the range of flows tested (4.3 to $\left.7.6 \mathrm{ft}^{3} / \mathrm{s}\right)$ are subject to larger errors.

\section{DISPERSION}

The selected dye tracer (rhodamine WT) mixes completely in water, therefore, tracking the movement of the dye will reflect the dispersion characteristics of the stream. Solute dispersion in a stream occurs in all three dimensions (lateral, vertical, and longitudinal). In a small stream, lateral and vertical dispersion of a tracer occurs in a short distance due to turbulent flow and the confining boundaries of the stream. Longitudinal dispersion, having no such boundaries, continues indefinitely. The effect of longitudinal dispersion on the dye plume as it moves downstream is clearly shown in figure 4. Dispersion elongates the dye plume by decreasing the dye concentration and increasing the total duration (arrival time of trailing edge minus arrival time of leading edge) downstream. A comparison of the dyeresponse curves for medium- and low-flow conditions indicates that longitudinal dispersion is more pronounced during lower flows in the study area. At the farthest downstream site (site $\mathrm{RC} 2$ ), the total duration of the dye plume increased from about 18 hours for the medium-flow test to about 64 hours for the low-flow test. The reason for the increased longitudinal dispersion at low-flow conditions is that dipersion is a time-based process. As flow conditions decrease, the pools exert a greater effect on streamflow, which corresponds to a decrease in the median water velocity (as shown by the traveltimes of the two dye-tracing tests). This slower water movement gives more time for longitudinal dispersion to take place. 
Velocities also were used to obtain incremental time of travel for the leading and trailing edge of the dye plume (figs. 5-7). The expected total duration of a dye plume for a variety of discharges at injection site $\mathrm{RC} 18$ is shown in figure 8. A linear relation does not exist between discharge at the upstream end of the study area and total duration of the dye plume (longitudinal dispersion). Each incremental decrease in discharge at site $\mathrm{RC} 18$ corresponds to a nonlinear increase in the total duration of the dye plume. When the discharge is less than $2.5 \mathrm{ft}^{3} / \mathrm{s}$ at injection site $\mathrm{RC} 18$, generally there is no streamflow at sampling site RC2 because of complete loss of flow through the streambed to underlying aquifers.

Following a discrete parcel of water downstream through the study area becomes increasingly difficult because of dispersion as the discharge at site RC18 decreases. A sample collected at the time determined by calculating time of travel of the peak concentration (fig. 6), however, is most representative of the water sampled at site RC18.

\section{SUMMARY}

Time of travel of a discrete parcel of water in a 9.4-river-mi reach of Roberts Creek in northwestern Clayton County, Iowa, was determined using dye-tracing techniques. Two dye-tracing tests were conducted in the study area. A medium-flow test was conducted during March 20-22, 1990, at a flow that is equaled or exceeded about 48 percent. A lowflow test was conducted during April 30 to May 12,1990 , at a flow that is equaled or exceeded about 80 percent. One dye-injection site and

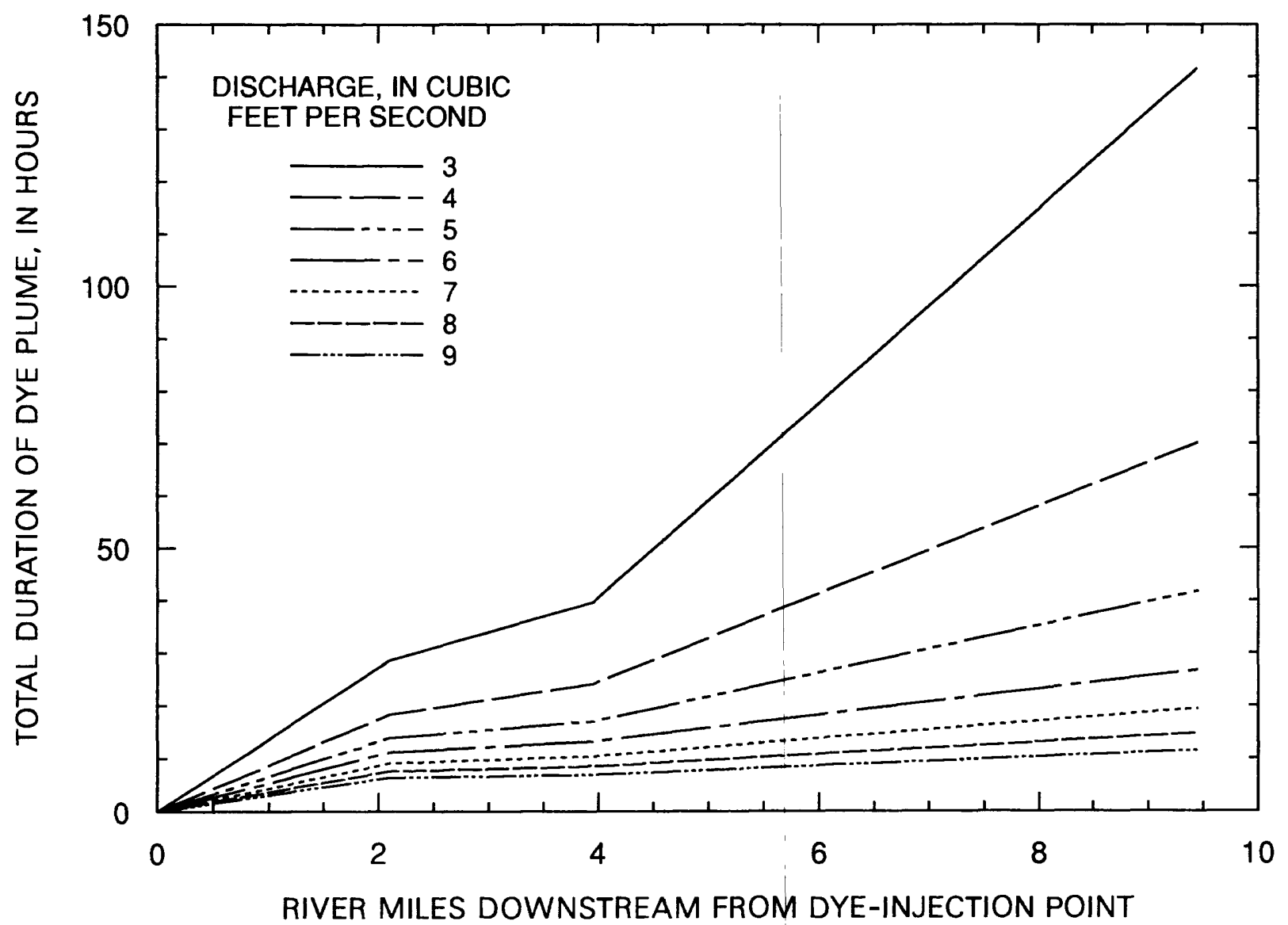

Figure 8. Duration of dye plume in relation to discharge at site RC18. 
three sampling sites were used to measure time of travel. Rhodamine WT dye was the tracer used. Data obtained from the dye-tracing tests were used to estimate the time required for soluble substances to move to any point downstream from site RC18 for a range of streamflows occurring at site RC18.

During a median-flow condition, the peak concentration of the dye plume moved through the study area in about 59 hours at an average velocity of $0.23 \mathrm{ft} / \mathrm{s}$. The average velocity of the peak concentration of the dye plume was $0.27 \mathrm{ft} / \mathrm{s}$ through the subreach from site RC18 to site $\mathrm{RC} 19,0.33 \mathrm{ft} / \mathrm{s}$ through the subreach from site RC19 to site RC24, and $0.20 \mathrm{ft} / \mathrm{s}$ through the subreach from site RC24 to site $\mathrm{RC} 2$.

During a low-flow condition, the peak concentration of the dye plume moved through the study area in about 200 hours at an average velocity of $0.07 \mathrm{ft} / \mathrm{s}$. The average velocity of the peak concentration of the dye plume was $0.10 \mathrm{ft} / \mathrm{s}$ through the subreach from site RC18 to site $\mathrm{RC} 19,0.14 \mathrm{ft} / \mathrm{s}$ through the subreach from site RC19 to site RC24, and $0.05 \mathrm{ft} / \mathrm{s}$ through the subreach from site RC24 to site $\mathrm{RC} 2$.

Incremental velocity curves were developed to estimate the time required for soluble substances to move to any point downstream from injection site $\mathrm{RC} 18$ for a range of discharges. The information required to use these predictive curves are stream distance from site RC18 and stream discharge at site $\mathrm{RC} 18$.

The data obtained from this study to compute time of travel are subject to the following limitations: (1) the data are applicable only during steady or gradually changing streamflow conditions; (2) the data are most accurate during fair weather conditions; (3) the data are valid only for water or water-soluble constituents; (4) the data are accurate only within the study area; and (5) the data might be subject to error when discharge substantially deviates from the range of discharge tested.

Longitudinal dispersion elongates the dye plume by decreasing dye concentration and increasing the total duration with passage downstream. Longitudinal dispersion increases nonlinearly as discharge decreases at site RC18. At the farthest downstream site (site $\mathrm{RC} 2$ ), the total duration of the dye plume increased from about 18 hours during a medium-flow condition to about 64 hours during a low-flow condition. The use of the peak-concentration time-of-travel computation for downstream sampling should lead to the best representation of water collected at site RC18.

\section{SELECTED REFERENCES}

Goolsby, D.A., Thurman, E.M., Kolpin, D.W., and Detroy, M.G., 1989, A reconnaissance for triazine herbicides in surface waters of the upper midwestern United States, U.S. Geological Survey Second National Symposium on Water Quality--Abstracts of the Technical Sessions, Orlando, Florida, November 12-17, 1989: U.S. Geological Survey Open-File Report 89-409, p. 31.

Hallberg, G.R., Hoyer, B.E., Bettis, E.A., and Libra, R.D., 1983, Hydrogeology, water quality, and land management in the Big Spring Basin, Clayton County, Iowa: Iowa Department of Natural Resources, Geological Survey Bureau Open-File Report 83-3, 191 p.

Kalkhoff, S.J., 1989, Hydrologic data for the Big Spring Basin, Clayton County, Iowa, water year 1988: U.S. Geological Survey Open-File Report 89-230, 44 p. 
Kalkhoff, S.J., and Kuzniar, R.J., 1990, Hydrologic data for the Big Spring Basin, Clayton County, Iowa, water year 1989: U.S. Geological Survey Open-File Report 91-63, $66 \mathrm{p}$.

Kilpatrick, F.A., and Wilson, J.F., 1989, Measurement of time of travel in streams by dye tracing: U.S. Geological Survey Techniques of Water-Resources Investigations, Book 3, Chapter A9, 27 p.

Schuman, G.E., Burwell, R.E., Piest, R.F., and Spomer, R.G., 1973, Nitrogen losses in surface runoff from agricultural watersheds on Missouri Valley loess: Journal of Environmental Quality, v. 2, no. 2, p. 299302.

Steinheimer, T.R., and Johnson, S.M., 1986, Investigation of the possible formation of diethylnitrosamine resulting from the uses of rhodamine WT dye as a tracer in river waters, in Subitzky, Seymour, ed., Selected papers in the hydrologic sciences 1986: U.S. Geological Survey Water-Supply Paper 2290, p. 37-49.

Wilson, J.F., Cobb, E.D., and Kilpatrick, F.A., 1986, Fluorometric procedures for dye tracing: U.S. Geological Survey Techniques of Water-Resources Investigations, Book 3, Chapter A12, 34 p.

University Hygienic Laboratory, 1977, Water quality survey of the Iowa River during a rainfall runoff period: Iowa City, The University of Iowa Report 77-5, 30 p.

-----1979, Water quality survey of the Timber Creek Basin: Iowa City, The University of Iowa Report 79-30, 19 p.

-----1983, Yellow River rainfall runoff and low-flow water quality studies: Iowa City, The University of Iowa Report 83-3, 55 p. 